\title{
PENGARUH PRENATAL YOGA TERHADAP KONTRAKSI UTERUS DAN PERUBAHAN KADAR HORMON ENDORPHIN PADA IBU PRIMIGRAVIDA STUDI KASUS DI PUSKESMAS KADUGEDE KUNINGAN JAWA BARAT
}

\author{
Anggit Kartikasari ${ }^{1}$, Soeharyo Hadisaputro ${ }^{2}$, Sri Sumarni ${ }^{3}$ \\ ${ }^{1}$ STIKes Kuningan, ${ }^{2}$ Universitas Diponegoro, ${ }^{3}$ Poltekkes Kemenkes Semarang \\ anggit8616@gmail.com
}

\begin{abstract}
ABSTRAK
Mempersiapkan kondisi fisik baik kondisi otot-otot maupun persendian yang berperan dalam proses persalinan dan mempersiapkan kondisi psikis ibu terutama menumbuhkan kepercayaan diri dalam menghadapi persalinan dapat dilakukan dengan latihan prenatal yoga. Menjelaskan pengaruh prenatal yoga terhadap kualitas persalinan Ibu Primigravida.

Metode yang digunakan quasi-experimental rancangan Non-Equivalent Control Group Desain. Sampel adalah ibu primigravida trimester III, pengambilan sampel dengan cara purposive sampling. Analisis bivariat menggunakan independent t-test dan paired t-test.

Hasil penelitian ini ada pengaruh prenatal yoga terhadap kontraksi uterus $(p=0,000)$, ada pengaruh prenatal yoga terhadap perubahan kadar hormon endorphin pada kelompok perlakuan $(\mathrm{p}=0,002)$, tidak ada pengaruh perubahan kadar hormon endorphin pada kelompok kontrol $(\mathrm{p}=0,074)$. prenatal yoga dapat mempengaruhi lama persalinan ibu menjadi lebih cepat, kontraksi uterus menjadi kuat dan ada peningkatan kadar hormon endorphin. Perlunya mengajarkan prenatal yoga pada ibu-ibu hamil dan membuat kelas-kelas antenatal pada setiap Bidan Praktek Swasta atau Puskesmas.
\end{abstract}

\section{Kata Kunci : Prenatal Yoga, Lama Persalinan, Kontraksi Uterus, Kadar Endorphin}

\section{LATAR BELAKANG}

Persalinan yang alami dan lancar ini dapat dicapai jika uterus berkontraksi dengan baik, ritmis dan kuat dengan segmen bawah rahim, serviks, dan otot-otot dasar panggul dalam keadaan relaksasi, sehingga bayi dengan mudah melewati jalan lahir. Keadaan ini dapat dicapai dengan bantuan wanita hamil itu sendiri yang merupakan ketenangan dan relaksasi tubuh yang sempurna. Beberapa diantaranya adalah berupa latihan-latihan 
JURNAL ILMU KESEHATAN BHAKTI HUSADA:

HEALTH SCIENCES JOURNAL, VOL. 11 NO. 01, JUNI 2020 DOI: 10.34305/JIKBH.V11I1.147

fisik yang dapat dijalankan sebelum, selama, dan setelah kehamilan. Latihanlatihan tersebut pada dasarnya bertujuan untuk menyehatkan ibu dan janin jika dilaksanakan dengan tepat. Seorang ibu hamil dengan kehamilan normal atau tanpa kontraindikasi sebaiknya didukung untuk melaksanakan latihan fisik dengan intensitas yang sedang untuk memperoleh manfaat selama kehamilan dan proses (Norwitz \& Schorge, 2008).

Prenatal yoga merupakan suatu program latihan bagi ibu hamil sehat untuk mempersiapkan kondisi fisik ibu dengan menjaga kondisi otot-otot dan persendian yang berperan dalam proses persalinan, serta mempersiapkan kondisi psikis ibu terutama menumbuhkan kepercayaan diri dalam menghadapi persalinan. Prenatal yoga memberi manfaat terhadap komponen biomotorik otot yang dilatih, dan juga dapat meningkatkan daya tahan kardiorespirasi dengan meningkatkan konsumsi oksigen. Senam atau latihan selama kehamilan memberikan efek positif terhadap pembukaan serviks dan aktivitas uterus yang terkoordinasi saat persalinan, juga ditemukan secara bermakna onset persalinan yang lebih awal dan lama persalinan yang lebih singkat dibandingkan dengan yang tidak melanjutkan prenatal yoga (Pratignyo, 2014).

Beberapa penelitian sebelumnya yang membuktikan bahwa yoga sangat
Ciptaan disebarluaskan di bawah

Lisensi Creative Commons Atribusi-

NonKomersial-BerbagiSerupa 4.0 Internasional (c) () (S)

bermanfaat bagi ibu hamil, menurut penelitian Trisnanto, di kecamatan Ngronggot dengan hasil ada pengaruh senam prenatal yoga terhadap penurunan kecemasan pada ibu hamil dengan uji statistik menggunakan uji paired t-test menunjukkan signifikan output $p=0.000 \alpha$ $\leq 0.05$. (Trisnanto, 2014). penelitian yang sama juga dilakukan oleh Wijaya, dengan hasil penelitian menunjukkan bahwa nilai $\mathrm{Z}$ hitung sebesar -3,537 lebih besar dari nilai $\mathrm{Z}$ tabel 1,96 dan nilai $p<0,05$ yang berarti $\mathrm{H}_{0}$ ditolak dan $\mathrm{H}_{\mathrm{a}}$ diterima sehingga dapat disimpulkan bahwa ada pengaruh yang signifikan yoga pranayama terhadap penurunan tingkat kecemasan pada Ibu hamil Trimester III (Wijaya \& Agustini, 2014). Penelitian terkait dengan yoga juga dilakukan oleh Narendran, bahwa khasiat yoga mempengaruhi outcome persalinan, Jumlah bayi dengan berat badan lahir $\geq$ 2500 gram secara signifikan lebih tinggi ( $p$ $<0,01)$ di kelompok yoga. Persalinan prematur secara signifikan lebih rendah $(p<$ 0,0006) dalam kelompok yoga. Komplikasi seperti terisolasi intrauterine growth retardation (IUGR) $(p<0,003)$ dan hipertensi akibat kehamilan (PIH) dengan terkait IUGR $(p<0.025)$ juga secara signifikan lebih rendah pada kelompok yoga. Tidak ada yang merugikan yang signifikan dalam kelompok yoga (Narendran et al., 2005). 
JURNAL ILMU KESEHATAN BHAKTI HUSADA:

HEALTH SCIENCES JOURNAL, VOL. 11 NO. 01, JUNI 2020 DOI: 10.34305/JIKBH.V11І1.147

Berdasarkan hal tersebut peneliti ingin mengetahui Pengaruh Prenatal Yoga Terhadap kontraksi uterus dan Perubahan Kadar hormon endorphin pada Ibu Primigravida.

\section{METODOLOGI PENELITIAN}

Jenis penelitian ini adalah kuantitatif dengan metode penelitian quasiexperimental (eksperimen semu) rancangan Non-Equivalent Control Group Desain, Desain ini hampir mirip dengan pretestposttest control group design, tetapi pada desain ini kelompok eksperimen dan kelompok kontrol tidak dipilih secara random. Dalam desain ini, baik kelompok eksperimen maupun kelompok kontrol dibandingkan, kendati kelompok tersebut dipilih dan ditempatkan tanpa melalui random. Dua kelompok yang ada diberi pretest, kemudian diberikan perlakuan, dan terakhir diberikan posttest (Cook et al., 1979)

Populasi dalam penelitian ini adalah semua ibu hamil trimester tiga yang berada di wilayah kerja Puskesmas Kadugede kabupaten kuningan.Teknik pengambilan sampel dalam penelitian ini menggunakan purposive sampling dengan kriteria inklusi dan eksklusi. Adapun kriteria inklusinya adalah primigravida, tidak memiliki komplikasi kehamilan (non-risiko), usia ibu bersalin 20 - 35 tahun, beban pekerjaan tidak dibantu oleh asisten rumah tangga,
Ciptaan disebarluaskan di bawah

Lisensi Creative Commons Atribusi-

NonKomersial-BerbagiSerupa 4.0 Internasional

usia kehamilan > 36 minggu, dan kriteria ekslusinya adalah ibu yang tidak bersedia menjadi responden, ibu yang tidak mengetahui letak janin normal atau tidak. Diperkirakan $50 \%$ kemungkinan sampel drop out maka besar sampel yang dibutuhkan masing-masing kelompok adalah 14 responden, sehingga secara keseluruhan dibutuhkan sampel sebanyak 28 responden. Analisis univariat digunakan untuk mengidentifikasi lamanya Kala I, kontraksi uterus dan kadar hormone endorphin. Analisis bivariat untuk menguji pengaruh prenatal yoga terhadap kontraksi uterus pada ibu primigravida digunakan uji $\mathrm{t}$ tidak berpasangan, untuk menguji perubahan kadar hormon endorphin setelah melakukan prenatal yoga digunakan uji t berpasangan.

\section{HASIL PENELITIAN}

Pengumpulan data penelitian ini dilakukan pada bulan Desember 2015 sampai bulan Februari 2016. Jumlah responden pada penelitian ini sebanyak 28 orang akan tetapi pada saat penelitian berlangsung ada 3 orang drop out dikarenakan sebelum pelaksanaan yoga minggu ke 3 dan pengambilan darah setelah perlakuan sudah melahirkan sehingga responden menjadi 25 orang, yaitu 13 orang responden sebagai kontrol dan 12 orang responden yang diberikan perlakuan prenatal yoga. Dalam penelitian ini 
JURNAL ILMU KESEHATAN BHAKTI HUSADA:

HEALTH SCIENCES JOURNAL, VOL. 11 NO. 01, JUNI 2020

DOI: 10.34305/JIKBH.V11I1.147

kontraksi uterus diukur pada saat akhir kala

I persalinan.
Ciptaan disebarluaskan di bawah

Lisensi Creative Commons Atribusi-

NonKomersial-BerbagiSerupa 4.0 Internasional.

Tabel 1 Distribusi Frekuensi Karakteristik Ibu Berdasarkan Ukuran

Panggul Ibu Primigravida Di Wilayah Kerja Puskesmas Kadugede Kabupaten Kuningan Tahun 2015-2016.

\begin{tabular}{|c|c|c|c|c|c|c|}
\hline Ukuran Panggul & Kelompok & $\mathrm{N}$ & Mean & SD & Min-mak & $\begin{array}{c}\mathrm{p} \\
\text { value }\end{array}$ \\
\hline \multirow{2}{*}{ Distansia Spinarum } & Perlakuan & 12 & 24,97 & $\begin{array}{c}0,9 \\
9\end{array}$ & $23-26$ & \multirow{2}{*}{$\begin{array}{c}0,74 \\
1\end{array}$} \\
\hline & Kontrol & 13 & 24,81 & $\begin{array}{c}0,9 \\
5\end{array}$ & $23-26$ & \\
\hline \multirow{2}{*}{ Distansia Kristarum } & Perlakuan & 12 & 27,77 & $\begin{array}{c}1,1 \\
2\end{array}$ & $26-29$ & \multirow{2}{*}{$\begin{array}{c}0,63 \\
3\end{array}$} \\
\hline & Kontrol & 13 & 27,62 & $\begin{array}{c}0,9 \\
5\end{array}$ & $26-28,7$ & \\
\hline \multirow{2}{*}{ Distansia Tuberum } & Perlakuan & 12 & 10,78 & $\begin{array}{c}0,2 \\
0\end{array}$ & $10,5-11$ & \multirow{2}{*}{$\begin{array}{c}0,75 \\
4\end{array}$} \\
\hline & Kontrol & 13 & 10,78 & $\begin{array}{c}0,1 \\
9 \\
\end{array}$ & $10,5-11$ & \\
\hline \multirow{2}{*}{ Konjugata Eksterna } & Perlakuan & 12 & 19,21 & $\begin{array}{c}0,7 \\
4\end{array}$ & $18-20$ & \multirow{2}{*}{$\begin{array}{c}0,96 \\
2\end{array}$} \\
\hline & Kontrol & 13 & 18,97 & $\begin{array}{c}0,7 \\
4\end{array}$ & $18-20$ & \\
\hline \multirow{2}{*}{ Lingkar Panggul } & Perlakuan & 12 & 85,42 & $\begin{array}{c}3,7 \\
0\end{array}$ & $80-90$ & \multirow{2}{*}{$\begin{array}{c}0,47 \\
5\end{array}$} \\
\hline & Kontrol & 13 & 85,69 & 2,95 & $80-90$ & \\
\hline
\end{tabular}

Independent $t$-test

Tabel 2 Distribusi Frekuensi Karakteristik Ibu Berdasarkan Kecemasan

\begin{tabular}{ccccccc}
\hline Variabel & Kelompok & $\mathrm{n}$ & Mean & SD & Min-mak & p value \\
\hline \multirow{2}{*}{ Kecemasan } & Perlakuan & 12 & 56,47 & 10,64 & $36-77$ & \multirow{2}{*}{ Kontrol } \\
\cline { 2 - 6 } & 13 & 63,77 & 9,92 & $40-78$ &
\end{tabular}

Ibu Primigravida Di Wilayah Kerja Puskesmas Kadugede Kabupaten Kuningan Tahun 2015-2016

Independent $t$-test 
JURNAL ILMU KESEHATAN BHAKTI HUSADA:

HEALTH SCIENCES JOURNAL, VOL. 11 NO. 01, JUNI 2020

DOI: 10.34305/JIKBH.V11I1.147
Ciptaan disebarluaskan di bawah

Lisensi Creative Commons Atribusi-

NonKomersial-BerbagiSerupa 4.0

Tabel .3 Distribusi Frekuensi Karakteristik Ibu Berdasarkan Penolong

\section{Persalinan Ibu Primigravida Di Wilayah Kerja Puskesmas Kadugede Kabupaten}

Kuningan Tahun 2015-2016.

\begin{tabular}{ccc}
\hline Penolong persalinan & Jumlah & Persentase \\
\hline Tenaga kesehatan (bidan) & 25 & 100 \\
Non tenaga kesehatan & 0 & 0 \\
\hline Total & 25 & 100 \\
\hline
\end{tabular}

Berdasarkan tabel 1 hasil independent t-test membuktikan tidak ada perbedaan rerata ukuran panggul diantaranya : distansia spinarum antara kelompok perlakuan dan kelompok kontrol $(p=0,741)$, distansia kristarum antara kelompok perlakuan dan kelompok kontrol $(p=0,633)$, distansia tuberum antara kelompok perlakuan dan kelompok kontrol $(p=0,754)$, konjugata externa antara kelompok perlakuan dan kelompok kontrol $(p=0,962)$, lingkar panggul antara kelompok perlakuan dan kelompok kontrol $(p=0,475)$.

Berdasarkan tabel 2 hasil independent $t$-test membuktikan tidak ada perbedaan rerata kecemasan antara perlakuan dan kontrol $(p=0,849)$.
Berdasarkan tabel 3 dari 25 responden semua penolong persalinannya adalah bidan sebanyak 3 orang dan semua bidan telah mendapatkan pelatihan APN (Asuhan Persalinan Normal) dengan menggunakan 58 langkah.

\section{ANALISIS BIVARIAT}

Pengaruh prenatal yoga terhadap kontraksi uterus

Berdasarkan hasil perhitungan, diketahui bahwa nilai signifikansi untuk kontraksi uterus kelompok perlakuan sebesar 0,165 sedangkan kelompok kontrol sebesar 0,059, Karena nilai signifikansi lebih dari 0,05 maka distribusi lama persalinan normal, maka dapat dilanjutkan dengan melakukan independent t-test. 
Tabel 4 Analisis Pengaruh Prenatal Yoga Terhadap Kontraksi Uterus Di Wilayah Kerja Puskesmas Kadugede Kabupaten Kuningan Tahun 2015-2016.

\begin{tabular}{|c|c|c|c|c|c|c|c|}
\hline Variabel & Kelompok & Detik & $\mathrm{n}$ & Mean & $\mathrm{SD}$ & Min-mak & $\mathrm{p}$ value \\
\hline \multirow{12}{*}{$\begin{array}{c}\text { Kontraksi } \\
\text { uterus }\end{array}$} & \multirow{8}{*}{$\begin{array}{l}\text { Perlakuan } \\
\quad(\mathrm{n}=12)\end{array}$} & 43,5 & 1 & \multirow{8}{*}{49,46} & \multirow{8}{*}{4,55} & \multirow{8}{*}{$\begin{array}{l}43,5- \\
56,25\end{array}$} & \multirow{12}{*}{0,000} \\
\hline & & 45 & 3 & & & & \\
\hline & & 46 & 1 & & & & \\
\hline & & 50 & 3 & & & & \\
\hline & & 53 & 1 & & & & \\
\hline & & 53,75 & 1 & & & & \\
\hline & & 56 & 1 & & & & \\
\hline & & 56,25 & 1 & & & & \\
\hline & \multirow{4}{*}{$\begin{array}{c}\text { Kontrol } \\
(n=13)\end{array}$} & 37 & 2 & \multirow{4}{*}{38,69} & \multirow{4}{*}{1,11} & \multirow{4}{*}{$37-40$} & \\
\hline & & 38 & 4 & & & & \\
\hline & & 39 & 3 & & & & \\
\hline & & 40 & 4 & & & & \\
\hline
\end{tabular}

Independen t-test

Berdasarkan data dari tabel 5 pada kelompok perlakuan responden paling banyak mengalami kontraksi uterus 45 detik sebanyak 3 orang dan 50 detik sebanyak 3 orang, sedangkan pada kelompok kontrol responden paling banyak mengalami kontraksi uterus 38 detik sebanyak 4 orang dan 40 detik sebanyak 4 orang. Rata-rata kontraksi uterus kelompok perlakuan adalah 49,46 detik, standar deviasi sebesar 4,55 dengan variasi data antara 43,5-56,25, sedangkan kelompok kontrol adalah 38,69 detik, standar deviasi sebesar 1,11 dengan variasi data antara 3740. Uji independent $t$-test diperoleh hasil $p$ value sebesar 0,000 artinya bahwa ada pengaruh prenatal yoga terhadap kontraksi uterus.

\section{Pengaruh prenatal yoga terhadap} perubahan kadar hormon endorphin

Berdasarkan hasil perhitungan, diketahui bahwa nilai signifikansi untuk kelompok pre kontrol sebesar 0,175 dan untuk kelompok post kontrol sebesar 0,740, sedangkan untuk kelompok pre perlakuan sebesar 0,415 dan kelompok post perlakuan sebesar 0,820 Karena nilai signifikansi lebih dari 0,05 maka distribusi kelompok kontrol dan perlakuan pre, post normal, maka dapat dilanjutkan dengan melakukan uji t-test. 
Tabel 5 Analisis Pengaruh Prenatal Yoga Terhadap Perubahan Kadar Hormon Endorphin Di Wilayah Kerja Puskesmas Kadugede Kabupaten Kuningan Tahun 2015-2016.

\begin{tabular}{|c|c|c|c|c|c|c|}
\hline Variabel & Kelompok & & Mean & SD & Min-mak & $\begin{array}{c}\mathrm{p} \\
\text { value }\end{array}$ \\
\hline \multirow{8}{*}{$\begin{array}{l}\text { Hormon } \\
\text { endorphin }\end{array}$} & $\begin{array}{l}\text { Perlakuan } \\
\quad(\mathrm{n}=12)\end{array}$ & \multirow{2}{*}{ pre } & 285,07 & 144,93 & $75,76-519,19$ & \multirow{2}{*}{$0,147^{\mathrm{a}}$} \\
\hline & $\begin{array}{c}\text { Kontrol } \\
(n=13)\end{array}$ & & 364,17 & 204,96 & $54,75-648,99$ & \\
\hline & $\begin{array}{l}\text { Perlakuan } \\
\quad(n=12)\end{array}$ & \multirow{2}{*}{ post } & 382,87 & 106,37 & $292,30-568,93$ & \multirow{2}{*}{$0,094^{\mathrm{a}}$} \\
\hline & $\begin{array}{c}\text { Kontrol } \\
(\mathrm{n}=13)\end{array}$ & & 285,46 & 116,25 & $54,08-584,63$ & \\
\hline & Perlakuan & pre & 285,07 & 144,93 & $75,76-519,19$ & \multirow{2}{*}{$0,002^{\mathrm{b}}$} \\
\hline & $(n=12)$ & post & 382,87 & 106,37 & $292,30-568,93$ & \\
\hline & Kontrol & pre & 364,17 & 204,96 & $54,75-648,99$ & \multirow{2}{*}{$0,074^{\mathrm{b}}$} \\
\hline & $(n=13)$ & post & 285,46 & 116,25 & $54,08-584,63$ & \\
\hline
\end{tabular}

\section{Kadar hormon endorphin sebelum perlakuan}

Rata-rata kadar hormon endorphin kelompok pre perlakuan sebesar $285,07 \pm 144,93$ dengan varian data antara 75,76-519,19 dan pre kelompok kontrol sebesar $364,17 \pm 204,96$ dengan varian data antara 54,75-648,99. Hasil independent $t$ test diperoleh nilai $p=147$ artinya tidak ada perbedaan rerata perubahan kadar hormon endorphin sebelum intervensi antara kelompok perlakuan dan kontrol.

\section{Kadar hormon endorphin sebelum perlakuan}

Rata-rata kadar hormon endorphin kelompok post perlakuan sebesar $382,87 \pm 106,37$ dengan varian data antara
292,30-568,93 dan kelompok post kontrol sebesar 285,46 $\pm 116,25$ dengan varian data antara 54,08-584,63. Hasil independent ttest diperoleh nilai $p=0,94$, artinya tidak ada perbedaan rerata perubahan kadar hormon endorphin setelah intervensi antara kelompok perlakuan dan kontrol.

\section{Perbandingan kadar hormon endorphin} sebelum dan sesudah perlakuan antara kelompok

Kadar hormon endorphin pada kelompok perlakuan sebelum dan sesudah intervensi dengan uji paired $t$-test diperoleh nilai $p=0,002$, artinya ada pengaruh prenatal yoga terhadap perubahan kadar hormon endorphin pada kelompok perlakuan, sedangkan pada kelompok kontrol sebelum E-ISSN 2623-1204 P-ISSN 2252-9462 | 33 
JURNAL ILMU KESEHATAN BHAKTI HUSADA:

HEALTH SCIENCES JOURNAL, VOL. 11 NO. 01, JUNI 2020

DOI: 10.34305/JIKBH.V1111.147

dan sesudah intervensi dengan uji paired $t$ -

test diperoleh nilai $p=0,074$, artinya tidak
Ciptaan disebarluaskan di bawah

Lisensi Creative Commons Atribusi-

NonKomersial-BerbagiSerupa 4.0

Internasional

ada pengaruh perubahan kadar

endorphin pada kelompok kontrol.

Tabel 6 Analisis Beda Selisih Kadar Hormon Endorphin

\begin{tabular}{ccccccc}
\hline Variabel & Kelompok & & Mean & SD & Min-mak & $\begin{array}{c}\mathrm{p} \\
\text { value }\end{array}$ \\
\hline Beda & Perlakuan & pre & 124,80 & 104,86 & $1,49-3,20$ & 0,000 \\
Selisih & $\begin{array}{c}(\mathrm{n}=12) \\
\text { Kontrol }(\mathrm{n}=13)\end{array}$ & post & $-78,72$ & 145,27 & $-582,66-78$ & \\
\hline
\end{tabular}

Mann_Whitney

Berdasarkan tabel 7 bahwa rerata selisih kadar hormon endorphin pada kelompok perlakuan sebesar $124,80 \pm 104,86$, sedangkan pada kelompok kontrol sebesar $-78,72 \pm 145,27$. Hasil uji mann whitney diperoleh nilai $p=0,000$ yang artinya ada perbedaan rerata selisih kadar hormon endorphin antara kelompok kontrol dan perlakuan, artinya ada pengaruh prenatal yoga terhadap perubahan kadar hormon endorphin.

\section{PEMBAHASAN}

\section{Pengaruh prenatal yoga terhadap}

\section{kontraksi uterus}

Hasil penelitian menunjukkan bahwa dari Rata-rata kontraksi uterus kelompok perlakuan adalah 49,46 detik, sedangkan kelompok kontrol adalah 38,69 detik. Uji independent $t$-test diperoleh hasil $p$ value sebesar 0,000 artinya bahwa ada pengaruh prenatal yoga terhadap kontraksi uterus.

Kecemasan yang tinggi dapat menyebabkan produksi hormon oksitosin berkurang sehingga kontraksi uterus akan berkurang dan juga hormon kortisol juga berkurang sehingga produksi progesteron bertambah yang akhirnya menghambat persalinan karen progesteron berfungsi untuk menegangkan otot-otot rahim (Amalia, 2015).

Kontraksi uterus pada persalinan mempunyai sifat tersendiri. Kontraksi menimbulkan nyeri, merupakan satusatunya kontraksi normal muskulus. Kontraksi ini dikendalikan oleh saraf intrinsik, tidak disadari, tidak dapat diatur oleh ibu bersalin, baik frekuensi maupun lama kontraksi (Sumarah, 2009).

Kontraksi uterus merupakan serangkaian kontraksi rahim yang teratur karena otot-otot polos rahim yang bekerja dengan baik dan sempurna. Intensitas dan frekuensi kontraksi uterus bervariasi selama persalinan semakin meningkat waktu persalinan semakin maju. Latihan nafas, relaksasi dan afirmasi positif memberikan kesiapan mental, membantu memusatkan pikiran, memberi ketenangan dan kenyamanan sehingga asupan oksigen meningkat dan peredaran darah lancar. 
JURNAL ILMU KESEHATAN BHAKTI HUSADA:

HEALTH SCIENCES JOURNAL, VOL. 11 NO. 01, JUNI 2020 DOI: 10.34305/JIKBH.V11I1.147

Bonding ibu dan bayi memicu hormon oksitosin dan endorphin diproduksi oleh tubuh berguna untuk mengatur aktivitas kontraksi uterus, mempercepat proses dilatasi serviks, kecemasan berkurang, menghambat impuls nyeri sampai ke korteks serebri, mengurangi ketegangan otot-otot polos dan pembuluh darah serta menghemat energi pada saat persalinan (Shindu, 2009).

Prenatal yoga mempunyai kelebihan teknik nafas yoga memasuk lebih banyak $\mathrm{O}_{2}$ dibandingkan dengan teknik nafas kompensional. Asupan $\mathrm{O}_{2}$ yang memadai memicu peningkatan pengeluaran hormon endorphin sehingga ibu menjadi lebih tenang merasakan rasa nyeri persalinan. Selain itu pasokan $\mathrm{O}_{2}$ yang memadai mencegah terjadinya metabolisme anaerob sehingga kontraksi uterus tidak terganggu dan proses persalinan berjalan lancar. Teknik pernafasan dapat memperbaiki relaksasi otot-otot abdomen, otot-otot genitalia menjadi rileks, sehingga otot-otot tersebut tidak mengganggu penurunan janin (Simkin \& Bolding, 2004).

\section{Pengaruh prenatal yoga terhadap}

\section{perubahan kadar hormon endorphin}

Hasil penelitian menunjukkan bahwa nilai $p$ kelompok perlakuan sebesar 0,002 , artinya ada pengaruh prenatal yoga terhadap perubahan kadar hormon endorphin pada kelompok perlakuan,sedangkan nilai $p$ kelompok
Ciptaan disebarluaskan di bawah

Lisensi Creative Commons Atribusi-

NonKomersial-BerbagiSerupa 4.0

Internasional

kontrol sebesar 0,074, artinya tidak ada pengaruh perubahan kadar hormon endorphin pada kelompok kontrol.

Hal ini sejalan dengan penelitian Siswantoyo, (2010), didapatkan bahwa kadar beta endorphin pretest-posttest 45 menit terjadi peningkatan yang signifikan dengan $p=0,000$, dan pada pretest-posttest 24 jam juga terdapat peningkatan yang signifikan dengan $p=0,000$. Disimpulkan bahwa peningkatan kadar beta endorphin 45 menit setelah latihan jauh lebih tinggi dibanding dengan pengukuran 24 jam setelah latihan. Jarak waktu pengambilan 45 menit dan 24 jam telah menunjukkan adanya penurunan kadar beta endorphin. Terjadinya penurunan ini menunjukkan adanya indikasi ke arah pulih asal.

Olahraga terutama bila dilakukan secara rutin dan profesional, selain berfungsi menurunkan kadar hormonhormon stres, juga meningkatkan produksi endorphin. Olahraga dalam dosis tinggi, memberikan efek endorphin keluar dalam jumlah tinggi juga dan dapat membawa seseorang dalam kondisi euphoria dan amat sangat bahagia. Bahkan sampai beberapa jam setelah selesai berolahraga (Haruyama, 2011).

Berlatih yoga secara teratur juga dapat meningkatkan hormon endorphin secara maksimal. Hormon endorphin memiliki sifat yang mirip dengan petidin (meperidin, Demerol), morfin, dan heroin, 
JURNAL ILMU KESEHATAN BHAKTI HUSADA:

HEALTH SCIENCES JOURNAL, VOL. 11 NO. 01, JUNI 2020 DOI: 10.34305/JIKBH.V11I1.147

dan telah terbukti bekerja pada reseptor yang sama dari otak. Seperti oksitosin, endorphin disekresikan dari kelenjar hipofisis, dan kadarnya meningkat saat kehamilan, kelahiran, dan menyusui. Kadar hormon endorphin yang tinggi membantu ibu bersalin mengubah persepsi rasa nyerinya dan meningkat saat persalinan

\section{KESIMPULAN DAN SARAN}

\section{Kesimpulan}

Berdasarkan hasil penelitian dan pembahasan yang telah peneliti lakukan mengenai pengaruh prenatal yoga terhadap lamanya persalinan kala I dan perubahan kadar hormon endorphin pada ibu primigravida maka dapat diambil kesimpulan sebagai berikut:

1. Kontraksi uterus ibu hamil yang mengikuti prenatal yoga lebih kuat dibandingkan dengan ibu yang tidak mengikuti prenatal yoga. Ada pengaruh antara prenatal yoga dan kontraksi uterus

2. Ada pengaruh prenatal yoga terhadap perubahan kadar hormon endorphin setelah melakukan yoga.

\section{Saran}

Berdasarkan hasil penelitian dan pembahasan mengenai pengaruh prenatal yoga terhadap kontraksi uterus dan perubahan kadar hormon endorphin pada ibu primigravida, maka terdapat beberapa
Ciptaan disebarluaskan di bawah

Lisensi Creative Commons Atribusi-

NonKomersial-BerbagiSerupa 4.0 Internasional. saran yang dapat peneliti sampaikan yaitu sebagai berikut :

1. Bagi Ibu Hamil

Bagi setiap ibu hamil disarankan mengikuti prenatal yoga, karena dengan mengikuti prenatal yoga masa kehamilan memberikan kesiapan mental, membantu memusatkan pikiran, memberi ketenangan dan kenyamanan. Selain itu dengan prenatal yoga otot-otot yang berhubungan dengan persalinan akan terlatih sehingga proses berjalan lancar.

2. Bagi petugas kesehatan

Petugas kesehatan (Bidan) sebagai tenaga kesehatan terdepan diharapkan dapat memotivasi ibu hamil untuk melakukan prenatal yoga, selain itu bidan diharapkan dapat mempelajari prenatal yoga sehingga dapat mengajarkan prenatal yoga pada ibuibu hamil dan membuat kelas-kelas antenatal pada setiap BPS atau Puskesmas.

3. Bagi Peneliti Lain

Hasil penelitian ini dapat dijadikan sebagai salah satu referensi kepustakaan penelitian selanjutnya dan dapat melanjutkan penelitian yang lebih mendalam berkaitan dengan kelenturan jalan lahir.

\section{DAFTAR PUSTAKA}

Amalia, A. (2015). Tetap sehat dengan yoga. Jakarta Selata: Panda Medika.

Cook, T. D., Campbell, D. T., \& Day, A. (1979). Quasi-experimentation: Design \& analysis issues for field 
JURNAL ILMU KESEHATAN BHAKTI HUSADA:

HEALTH SCIENCES JOURNAL, VOL. 11 NO. 01, JUNI 2020

DOI: 10.34305/JIKBH.V1111.147

settings (Vol. 351). Houghton Mifflin Boston.

Haruyama, S. (2011). The miracle of endorphin: Sehat mudah dan praktis dengan hormon kebahagiaan. Bandung: Penerbit Kaifa.

Narendran, S., Nagarathna, R., Narendran, V., Gunasheela, S., \& Nagendra, H. R. R. (2005). Efficacy of yoga on pregnancy outcome. Journal of Alternative \& Complementary Medicine, 11(2), 237-244.

Norwitz, E., \& Schorge, J. O. (2008). At a glance obstetri dan ginekologi. Jakarta: Erlangga, 144.

Pratignyo, T. (2014). Yoga Ibu Hamil. Puspa Swara.

Shindu, P. (2009). Yoga Untuk Kehamilan Sehat, Bahagia dan Penuh Makna, Seri bugar. Bandung: Qonita Mirzan Pustaka.

Simkin, P., \& Bolding, A. (2004). Update on nonpharmacologic approaches to relieve labor pain and prevent suffering. Journal of Midwifery \& Women's Health, 49(6), 489-504.

Siswantoyo, S. (2010). Perubahan Kadar Beta Endorphin Akibat Latihan Olahraga Pernafasan (sebuah Kajian Psikoneuroendokrinologi pada Aktivitas Fisik). Buletin Penelitian Sistem Kesehatan, 13(2), 21231.

Sumarah. (2009). Perawatan Ibu Bersalin (Asuhan Kebidanan Pada Ibu Bersalin). Fitramaya.

Trisnanto. (2014). Pengaruh senam prenatal yoga terhadap penurunan kecemasan pada ibu hamil. Jurnal Kesehatan Stikes Satriya Bhakti Nganjuk, 1, 8292.

Wijaya, I. G. N. P., \& Agustini, I. G. A. R. (2014). PENGARUH YOGA PRANAYAMA TERHADAP KECEMASAN PADA IBU HAMIL TRIMESTER III DALAM MENGHADAPI PERSALINAN DI BPS IDA AYU PUTU SUARTIKA, Amd. Keb. Jurnal Dunia Kesehatan Volume 3 No 1 Juni 2014, 3(1). 